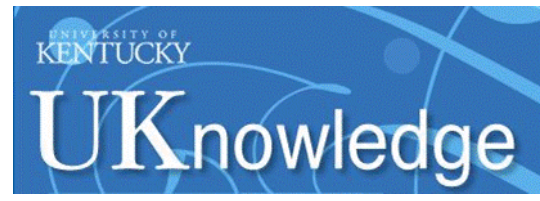

University of Kentucky

UKnowledge

August 1998

\title{
Reinterpreting Telepathy as Unusual Experiences of Empathy and Charisma
}

James M. Donovan

james.donovan@uky.edu

Follow this and additional works at: https://uknowledge.uky.edu/law_facpub

Part of the Psychology Commons

Right click to open a feedback form in a new tab to let us know how this document benefits you.

\section{Repository Citation}

Donovan, James M., "Reinterpreting Telepathy as Unusual Experiences of Empathy and Charisma" (1998). Law Faculty Scholarly Articles. 452.

https://uknowledge.uky.edu/law_facpub/452

This Article is brought to you for free and open access by the Law Faculty Publications at UKnowledge. It has been accepted for inclusion in Law Faculty Scholarly Articles by an authorized administrator of UKnowledge. For more information, please contact UKnowledge@lsv.uky.edu. 
Reinterpreting Telepathy as Unusual Experiences of Empathy and Charisma

This article is available at UKnowledge: https://uknowledge.uky.edu/law_facpub/452 
A Reprint from

\section{PERCEPTUAL AND MOTOR SKILLS}

August 1998

REINTERPRETING TELEPATHY AS UNUSUAL EXPERIENCES

OF EMPATHY AND CHARISMA

JAMES M. DONOVAN

Tulane University 
Perceptual and Motor.Skills, 1998, 87, 131-146. C Perceptual and Motor Skills 1998

\title{
REINTERPRETING TELEPATHY AS UNUSUAL EXPERIENCES OF EMPATHY AND CHARISMA'
}

\author{
JAMES M. DONOVAN
}

Tulane University

\begin{abstract}
Summary-Telepathy is often dismissed because it is judged to be contrary to the accepted facts of social psychology. This article argues that what is called telepathy may require nothing more than empathy and charisma and is reducible to these sociopsychological constructs. Two studies explore this hypothesis. In the first the proposed relationship is used to explain the sheep-goat effect. In the second study scores on charisma and empathy are used as direct predictors of telepathy scores. The results in combination support the interpretation of telepathy as phenomenologically impressive social psychological events which in less dramatic instances are termed empathy and charisma.
\end{abstract}

William James once observed that in a debate between mystics and scientists, mystics more often get the facts right, but the scientists have the upper hand in terms of the theories which explain those facts (James, 1956, p. 302). As such, mystics and others are probably correct that telepathy, defined as the "transmission of thought independently of the recognized channels of sense" (Fodor, 1966, p. 376), occurs. Efforts to explain this effect in terms of the "paranormal" or unknown have failed (Druckman \& Swets, 1988). Applying James' other observation that "science always takes a known kind of phenomenon, and tries to extend its range" (p. 321), a more successful research agenda may be that telepathy only appears to be an information-transfer "anomaly' (Rao \& Palmer, 1987). Instead, telepathy might be better understood in terms of more common social psychological processes, which, when "extended," become a phenomenologically distinctive event. In keeping with this idea, this paper considers whether telepathy cannot be deconstructed into unusual occurrences of charisma or empathy.

Charisma is defined as a "dramatic flair involving the desire and ability to communicate emotions and thereby inspire others" (Friedman, Riggio, \& Casella, 1988, p. 204). The "intense emotional state of the charismatic is transmitted spontaneously to onlookers" (Lindholm, 1990, p. 26). On the other hand, empathy is "the imaginative transposing of oneself into the thinking, feeling and acting of another and so structuring the world as he

'This article was possible only through the generous cooperation of many persons. Among them, Kathleen Carlin, Edward Fischer, Craig Hanson, Nancy Mullenax, Christina B. Turner. and Shana Walton helped collect data. Enduring thanks belong to my partner, the late Jorgc Vásconez. He was the only person l've met who carned a perfect Charisma score, which was a personal demonstration for me of the validity of the Affective Communication Test. Direct correspondence to James M. Donovan, Ph.D., Tulane Law Library, 6329 Freret, New Orleans, LA 70118-6231. The test decks described in this paper are available for loan to interested persons. 
does" (Dymond, 1949, p. 127). The "core of the empathic experience [is] a 'free-association' or loosening of self-other boundaries in allowing stimuli impinging on the other to be experienced by the self" (Strayer, 1987, p. 227).

Despite common assumptions to the contrary, empathy and charisma are not the simple results of subliminal cueing. At best such cueing might account for the information transfer, but not at all for the effect of that new information upon the receiver. In fact, very little is actually known about the mechanisms behind empathy and charisma. Empathy has been called a "riddle in social psychology" (Allport, 1968, p. 30), one which cannot be studied scientifically (Strayer, 1987, p. 235). Our present failure to explain fully the operation of these experiences, however, has neither detrimentally affected the acceptance of their prevalence, nor undermined the perception that they describe actual events of psychosocial interaction.

As much cannot be said about telepathy, another information-transfer process which is currently also unexplained. Donovan (1992) drew attention to the remarkably similar language which describes each of these three social psychological experiences, parallels which may suggest significant relationships between them. A second study (Donovan, 1997) compared the published experimental correlates of empathy, charisma, and telepathy (of which there are not many, since charisma has been rarely quantified) and showed that they are more alike than not, again suggesting a possible relationship. For example, women are significantly more prone to experience all three phenomena.

This article reports a third step in the progressive exploration of this thesis. If telepathy is experientially impressive empathy and charisma, then knowledge of the latter should be usable to explain or predict instances of the former. The next two sections attempt to test this claimed relationship.

Study 1: The Sheep-Goat Effect

Over fifty years ago, Gertrude Schmeidler noted an experimental effect within laboratory studies of extrasensory perception [ESP]. Subjects who believed ESP could or does occur consistently scored higher on ESP tests than those who believed ESP could not possibly happen [Schmeidler, 1943; this research was reviewed by Schmeidler and McConnell (1958)]. Palmer's (1971) review concluded that this pattern between beliefs and test scores is consistent, even if small (Schmeidler, 1988, p. 57) and may even be the "most consistent finding in experimental parapsychology" (cf. Irwin, 1989, p. 97; Brugger, Landis, \& Regard, 1990, p. 459; Broughton, 1991, p. 109). Termed the "Sheep-Goat Effect" as a description of the two classifications of subjects, "sheep" believe that ESP is possible and perform better than "goats," who believe that ESP is not possible. Schmeidler's original articula- 
tion of the sheep-goat effect limits "beliefs" to what the subject stated might occur in that particular experimental setting. Most subsequent research obscures this specification into more abstract positive or negative positions (cf. Schmeidler, 1985) so that the beliefs refer not to the immediate testing situation but to what is possible in the general run of life.

One limiting condition to the sheep-goat effect may be the public intent of the experiment, in which case the effect appears only when the goal is to elicit ESP. But if the experiment is designed to disprove ESP, the relationship may reverse, suggesting that "subjects tend to score in the direction that will provide evidence for their previously formed opinions" (Lovitts, 1981 , p. 294). This interpretation would also account for finding the sheep-goat effect in a single subject, using hypnosis to induce first one belief state and then the other (e.g., Grela, 1945).

One possible explanation of the sheep-goat effect is that "sheep" tend to underestimate the likelihood that repetitions will occur by chance. Thus they avoid them when told to guess randomly and, when these do occur, assume that there must be some cause (such as ESP) acting to generate the pattern (Brugger, et al., 1990). For these authors, ESP is not "Extra-Sensory Perception," but instead "Effect of Subjective Probability." It is unclear, however, why a consistent deviation from randomness would reliably generate higher-than-expected scores, since some systematic deviations should result in substandard performances, so that the combined result should be an expected mean performance. One could thus expect greater score variability within sheep but not necessarily the reported significantly greater means.

Taking the sheep-goat effect as established, the question becomes, Why does belief in the possibility of ESP have this positive relationship to ESP test performance?

The basis of belief is experience. Those who believe in ESP are those who have had personal experience with at least one of its manifestations (Anthony, 1982; McClenon, 1984; White, 1994), although some would reverse the relationship, holding that experience follows upon prior belief (Nanko, 1986, p. 237; Virtanen, 1990, p. 18).

Experience, in its turn, is a function of ability or predisposition. If telepathy is a function of empathy and charisma, those who possess these traits should experience more ESP phenomena. If this logic is correct (charisma and empathy lead to ESP experience, which leads to belief in ESP which is manifest as high ESP test scores), then the sheep-goat effect can be accounted for. Belief is based upon past experience of abilities which may be similar to the point of being identical to those required to perform well on present ESP tasks, hence belief correlates well with actual performance.

The present study examines whether these relationships are valid. The specific hypotheses tested are that (1) Those scoring high on charisma report 
more psychic experiences than do those who score low; (2) Those scoring high on empathy measures report more psychic experiences than do those scoring low; and (3) Those earning high ESP experience scores have more affirmative ESP beliefs than do those earning low experience scores.

Metbod

Subjects.-Students (150 women and 76 men; average respondent had completed the sophomore year of college and was between 21 and 25 years old) enrolled in undergraduate anthropology courses in four southern universities completed the inventories described below. All had the opportunity to decline participation without prejudice.

Inventories.-Friedman, Prince, Riggio, and DiMatteo (1980) designed the 13-item Affective Communication Test as a self-report measure for emotional expressiveness, which the authors equate with charisma. The authors reported the coefficient alpha for internal consistency to be .77 , and test-retest reliability to be .90 when test administrations occurred two months apart. Construct validity was ascertained by relating test scores with judgments of expressiveness by friends. For purposes of the present study, subjects responded to each item on a scale anchored by 0 (Not at all true of me) and 10 (Very true of me), for a total charisma score sum in the possible range of $0-130$. Alpha reliability for the present sample was .76 .

Hogan (1969) built the Hogan Empathy Scale by first using a Q-sort to identify what characteristics are deemed most typical of the empathic subject. This description was compared with Q-sort descriptions on file of military officers, research scientists, and student engineers. The correlations were interpreted as the Cognitive Empathy rating for each person. Using this rating to sort the subjects into high, middle, and low categories, items discriminating among subjects with high and low scores were taken from the California Psychological Inventory, the MMPI , and other in-house tests to yield a 64-item inventory. Average correlation between the final score on the Hogan Empathy Scale and the initial Cognitive Empathy rating was .62.

Using a true-false format, scores range from 0 to 64 . Alpha reliability for the present sample was .56. Cross and Sharpley (1982) stated that the Hogan Empathy Scale is a weak test, a conclusion bolstered by the low alpha coefficient of this study. They found that scores on 13 items correlated negatively with the total score, while another 30 were not significantly correlated. But as this test has been widely used, it is included here despite these flaws as the earlier uses can offer a potential basis of comparison.

As opposed to Cognitive Empathy measured by the Hogan Empathy Scale, Mehrabian and Epstein (1972) sought to operationalize an Emotional Empathy (cf. Krieger \& Reznikoff, 1992). The test's final 33 items were selected because they showed low correlations with social desirability, signifi- 
cant positive correlations with the total scale score, and content validity as ascertained from factor analysis of the larger item pool.

Dillard and Hunter (1989) held the composite score for the Emotional Empathy Scale is invalid. Because they found the scale to be multidimensional, the authors argued that, while useful information may be found within the subparts, the aggregation of the parts into a single score obscured useful information and was uninterpretable. Thus, only the Emotional Contagion subscale was used in the present study. This subscale has seven items, each eliciting a response anchored by 0 (Very strong disagreement) and 8 (Very strong agreement). Three items are reverse scored. The range of possible scores is 0 to 56 . Alpha reliability for the present sample was 74 .

Anthony (1982) devised the Psi-Experience Questionnaire as a standardized inventory with which to gauge psi experiences. Respondents are asked to rate the frequency of nine (Anthony's original eight, with one addition for the present study) different types of unusual experiences, such as whether the respondent had ever "mentally communicated with another" or "sensed the mind leaving the physical body." Ratings were anchored by 0 (Never) and 4 (Weekly or more). Possible total scores range from 0 to 36. Alpha reliability for the present sample was .81 .

In addition to measuring ESP experiences, quantification of ESP beliefs was needed in this study. Nanko (1986) began with the work of Tobacyk and Milford (1983) who factor analyzed 61 items questioning personal beliefs in various phenomena. Seven factors were identified: Traditional Religious Belief, Psi Beliefs, Witchcraft, Superstition, Spiritualism, Extraordinary Life Forms, and Precognition. The 25 clearest marker items were then selected to form a Paranormal Scale with small-to-moderate correlations between the subscales. Nanko extended the Paranormal Scale by adding 15 new items using a method similar to that of Tobacyk and Milford, starting with a larger pool of 63 new items and winnowing these down based upon test-retest reliabilities. Nanko placed the additional items into an eighth scale, Miscellaneous Psychic. These items covered topics not included in the earlier test such as beliefs in psychic surgery, paranormal healing, and firewalking. The authors reported a 4-wk. test-retest reliability of .90 $(N=25)$. Each item is marked by the respondent using anchors of 1 (Strongly Disagree) and 5 (Strongly Agree). Nine items are reversed scored. The range of possible scores is 40-200. Alpha reliability for the present sample was .94.

Results

Pearson correlations between scores on all measures are presented in Table 1 . The alpha criterion of significance is set at .01 for all analyses in this paper.

The group mean for all subjects on the charisma test was 73.7 ( $S D=$ 
TABLE 1

\begin{tabular}{|c|c|c|c|c|c|c|c|}
\hline Measure & Sex & 1 & 2 & 3 & 4 & 5 & 6 \\
\hline 1. Age Group & .01 & & & & & & \\
\hline 2. Education & -.07 & $.52^{\mathrm{a}}$ & & & & & \\
\hline 3. Extended Paranormal Belief Scale & .10 & -.09 & $-.19^{\mathrm{b}}$ & & & & \\
\hline $\begin{array}{l}\text { 4. Affective Commurication Test } \\
\text { (charisma) }\end{array}$ & $.19^{b}$ & -.01 & -.09 & .15 & & & \\
\hline 5. Emotional Empathy Scale & .09 & -.09 & .01 & .10 & -.15 & & \\
\hline 6. Hogan Empathy Scale & .01 & .11 & .07 & .12 & $.31^{\mathrm{b}}$ & -.06 & \\
\hline 7. Psi-experiences Questionnaire & .02 & -.09 & -.06 & $.50^{\mathrm{a}}$ & $.28^{\mathrm{b}}$ & -.04 & .16 \\
\hline
\end{tabular}
${ }^{\mathrm{a}} p<.001,{ }^{\mathrm{b}} .01>p>.001$.

18.8). This score was used to divide subjects into 117 above-average charisma test scorers and 109 below-average scorers. The above-average group reported a mean score on the Psi-Experiences Questionnaire of 6.8 ( $S D=$ $5.8, r_{\text {Charisma } \times \text { Exp }}=.09$ ), while the below-average group reported a mean score of $4.4\left(S D=4.3, r_{\text {(harisma } \times \text { Exp }}=.31\right)$. The difference was significant $\left(t_{214}=\right.$ $-3.46, p=.0006)$.

Each of the empathy measures was evaluated separately. The group mean for all subjects on the Hogan Empathy Scale was $37.6(S D=5.5)$. This score divided subjects into 112 above-average Cognitive Empathy scorers and 114 below-average scorers. The above-average group reported a mean score on the Psi-Experiences Questionnaire of $6.2\left(S D=5.5, r_{C . E m p . \times \operatorname{Exp}}=\right.$ $.14)$, while the below-average group reported a mean score of $5.1(S D=5.0$, $\left.r_{\text {(..Emp. } \times \text { Exp }}=.11\right)$. The difference was not significant $\left(t_{2211}=-1.59, p=.11\right)$.

The $t$ ratio for mean scores on the Emotional Empathy Scale's Emotional Contagion subscale were similarly nonsignificant $\left(t_{223}=0.27, p=.79\right)$. The group mean of $22.7(S D=9.7)$ divided the subjects into 114 above-average subscale scorers, who reported a mean score on the Psi-Experiences Questionnaire of $5.6\left(S D=5.2, r_{\mathrm{E} . \mathrm{Emp} \times \mathrm{Exp}}=.01\right)$, and 112 below-average Emotional Empathy scorers, who reported a mean experiences score of 5.8 $\left(S D=5.3, r_{\text {E. Limp. } \times \text { Exp }}=-.11\right)$.

All subjects combined reported a mean score on the Psi-Experiences Questionnaire of $5.7(S D=5.3)$. This result sorted the subjects into two groups, 94 reporting above-average scores and 132 reporting below-average scores. The above-average group scored an average of $131.2(S D=15.8$, $\left.r_{\text {Belief } \times \text { Exp }}=34\right)$ on the Extended Paranormal Belief Scale, while the belowaverage group had a mean score of $111.2\left(S D=23.4, r_{\text {Belicf } \times \text { Exp }}=.42\right)$. The difference was significant $\left(t_{223}=-7.65, p<.0001\right)$.

Discussion

The predicted relationship between scores for psi experience and psi 
belief was borne out: Subjects who reported familiarity with ESP experiences had much higher scores on beliefs in ESP. The hypothesis that telepathy, charisma, and empathy are experiences of a single kind therefore expects that these reported ESP experiences are in turn related to measures of charisma and empathy. In the case of charisma, the prediction was accurate: Individuals with above-average scores on charisma reported above-average frequency of ESP experiences.

Neither measure of empathy yielded the predicted relationship, although it may be noted that the Hogan Empathy Scale shows better promise at meaningfully sorting subjects into high-versus-low scorers on a scale of ESP experiences than does the Emotional Empathy Scale's Emotional Contagion subscale. A plausible interpretation is the known limitations of self-report scales for empathy (Eisenberg \& Lennon, 1983; Ickes, Stinson, Bissonnette, \& Garcia, 1990; Levenson \& Ruef, 1992). A performance measure of empathy, modeled after that described by Dymond (1949), may yield results more in keeping with the hypotheses.

\section{Study 2: The Use of Charisma and Empathy Scores} to Predict Performance on a Telepathy Test

The preceding section suggests that scores on charisma, and perhaps empathy, correlate with higher telepathy scoring via self-reports of experience and belief. The present section examines more directly the assertion that scores on empathy and charisma can predict actual performance on a telepathy test.

Three hypotheses were that (1) Scores on a telepathy test will correlate with the charisma scores of the agent or "sender" (telepathy is the result of mental "reaching out"); (2) Scores on a telepathy test will correlate with the empathy scores of the percipient or "receiver" (telepathy is the result of mental "gathering in"); and (3) Scores on a telepathy test will correlate with the combined empathy and charisma scores of the partners (telepathy is the result of the collaborative acts of mental "reaching out" and "gathering in").

\section{Metbod}

Subjects.-Fourteen subjects ( 7 men, 7 women) responded to a combination of newspaper solicitations and word-of-mouth among campus students and staff seeking participants in an ESP experiment. No one was rejected or discouraged from participating. Ages ranged from 18 to 45 years, with a mean of $28.4 \mathrm{yr} .(S D=7.5)$. Although some participants were already acquainted with each other, in only one case was a test pair composed of previously acquainted subjects. All subjects were assumed to possess normal color vision; ways in which color-blindness could complicate the present design or be turned to advantage in other venues were discussed by Carr 
(1983). ${ }^{2}$ All subjects were unaware of the hypotheses until posttreatment debriefing.

Stimuli-Because the test procedure would be long and repetitious, two target decks of 25 cards each were designed to introduce interest-renewing novelty half-way through the experiment (Rhine, 1953). Each card simultaneously presented an intellectual target (the color of the cards) and an emotional target (the affective response of the agent to each card). As a rule, each color was associated with two possible emotions to minimize any single correspondence between color and emotion. Green, for instance, could be associated with either "vigor of health and life" or "the pallor of rot and death." Construction of each deck is described separately.

The first was Deck A. Levy (1984) identified five colors which evoked predictable emotional responses from viewers, Color-Aid codes BVBT3, GBGH, ROH, GBGT4, and YGYS3. 'For example, the light, slightly grayed bluish-violet of BVBT3 "equated with both sadness and fatigue," while YGYS3, a dark, greenish-yellow mustard "inspired a sense of some sadness and anger but virtually no vigor" (p. 61). Levy's results for three colors (GBGT4, YGYS3, and ROH) were replicated by Gardano (1986), the relationship being valid cross-culturally (cf. D'Andrade \& Egan, 1974; D'Andrade, 1990). All emotional terms used to characterize these five colors were listed and then combined into five categories: SAD AND HURT, ANGRY, TIRED ("fatigue," "no vigor," and "relaxation"), ENERGETIC ("vigor" and "tension"), and INSECURE ("confusion" and "self-effacement").

The second was Deck B. Berlin and Kay (1969) discovered that the color spectrum is not divided arbitrarily by human populations. Knowing how many color terms a language had, the authors were able to predict to what colors they referred. They attributed this pattern to the higher perceptual salience of particular colors, the first five of which were White, Black, Red, Green, and Yellow. Since colors which were most perceptually (visually) salient might also be better communicated via ESP, Deck B includes these colors operationalized as Chromarama colors 7541, 7591, 6163, 6423, and 6003 , respectively. Emotional terms were attached to each color from the list provided by Birren (1950, p. 143). These terms were collapsed into

\footnotetext{
${ }^{2}$ The most common form of color-blindness is red-green. In the extremcly unlikely event that one of the subjects was a dichromat, this condition would have most affected the results using Deck $B$, as only this deck had true red and green cards. Since results in this study did not differ by deck, it is unlikely that color-blindness was a factor. Still, it should have been tested for, and further study should remedy this oversight.

'These manufacturer's codes permit exact replication of the target decks. Because the meanings of these codes are probably unfamiliar to the reader, the approximate placement of each among the more familiar Munsell color chips used by Berlin and Kay (1969) is given here: BVBT3 = D35 (bluish-violet), $\mathrm{ROH}=\mathrm{G} 5$ (red-orange), GBGT4=E23 (light blue-green), YGYS3 $=\mathrm{C} 14$ (greenish-yellow mustard), and $\mathrm{CBC}(\mathrm{SH}=\mathrm{H} 25$ (dark green) .
} 
five categories labeled INTENSE AND PASSIONATE ("intensity," "rage," "rapacity," "passion," and "fierceness"), PLAYFUL AND LIGHT-HEARTED ("normality," "happy," "comedy," and "high-spirit"), STRONG AND HEALTHY ("brightness of spirit" and "healthy"), EMOTIONALLY DEPRESSED ("negation of spirit," "guilt," and "terror"), and PHYSICALLY WEAK ("death," "disease," "ghastliness," and "tranquility").

The face of each colored card of both decks featured black photocopied graphics from Fenton and Morrissett (1990). Since most colors could evoke either of two possible emotional responses, each graphic was selected to highlight one over the other for that particular card. For example, Yellow in Deck B was divided between the STRONG AND HEALTHY and the PLAYFUL AND LIGHT-HEARTED categories. Graphics distinguished between the two: one card (B17) showed a man doing a bicep curl for STRONG AND HEALTHY, while another Yellow card (B13) displayed two kittens playing with balls to communicate PLAYFUL AND LIGHTHEARTED. When completed, each of the 25 cards simultaneously presented an intellectual target (the physical color) and an emotional target (the reaction of the agent to the combined stimulus of card color and evocative graphic).

Colors and emotional descriptors intersected in Deck A with the following result: BVBT3 (3 SAD AND HURT, 2 TIRED), YGYS3 (2 SAD AND HURT, 2 ANGRY, 1 TIRED), GBGH (3 ANGRY, 2 INSECURE), GBGT4 (2 TIRED, 3 INSECURE), and ROH (5 ENERGETIC). Deck B provided the following combinations: White $(3$ STRONG AND HEALTHY, 2 PLAYFUL AND LIGHT-HEARTED), Yellow (2 STRONG AND HEALTHY, 3 PLAYFUL AND LIGHT-HEARTED), Black (3 EMOTIONALLY DISTRESSED, 2 PHYSICALLY WEAK), Green (2 EMOTIONALLY DEPRESSED, 3 PHYSICALLY WEAK), and Red (5 INTENSE AND PASSIONATE).

On the back of each card was a unique identifier which specified the deck (A or B) and a number drawn from a table of random numbers. Each of five judges (opportunistically solicited and otherwise unassociated with the project and unfamiliar with the hypotheses) was presented with a list of the five emotional categories each deck was designed to elicit and asked to sort each card of each deck into whichever of the categories thought best to fit the card. Any card which was not correctly sorted by at least three judges was redesigned with a better graphic which would more reliably elicit the intended emotional response. Two cards in Deck A were thereby altered, as were five Deck B cards.

Personality measures.-Charisma was measured by the Affective Communication Test (Friedman, et al., 1980). Each of the 13 questions was rated on a scale from 1 to 9, which were summed for a total charisma score. Em- 
pathy was measured using the Emotional Empathy Scale's Emotional Contagion subscale and the Hogan Empathy Scale. To correct for their known limitations, the two empathy scales were combined into a single score via multiplication. This strategy generated one score which reflected the dual nature of empathy as being both a cognitive and emotional phenomenon. Multiplication tended to weight the new score in favor of Cognitive Empathy, which had performed better than Emotional Empathy in Study 1.

Procedure.-Each subject received a packet containing in order the following: (1) a covering letter thanking them for participating, explaining the questionnaires, describing the test procedures, and detailing the schedule for the test day, (2) a consent form, (3) the Hogan Empathy Scale, (4) the Affective Communication Test, (5) the Emotional Empathy Scale's Emotional Contagion subscale, and (6) the Myers-Briggs Type Indicator, Form G (the results of which are not included here). The packet was returned to the experimenter for scoring.

On the day of the study, subjects came to a specially prepared conference room in which four tables were arranged in a two-by-two pattern. This arrangement doubled the distance between members of a pair to a total of 58 in. A cloth partition between the tables obscured the view of the partners. Subjects were assigned partners and allowed a brief period of about 30 minutes for social interaction under the assumption that such was required for the effects of charisma and empathy.

Seated opposite, but out of view of their partners, subjects received a recording packet. Alternating in sets of five were agent sheets, percipientDeck A sheets, and percipient-Deck B sheets. At any given instance four pairs were using one deck, while the other three used the other deck, with these two groups interspersed. All persons on one side of the table simultaneously played the same role of either agent or percipient.

Using a taped protocol, agents were instructed to look at the first card. After 10 sec., they received the command to "record," whereupon the agent recorded the identifier from the back of the card onto the agent's record sheet. The random-number identifiers for each card assured that if an agent incorrectly recorded a target card (for example, forgetting to write it down), he could not fill in the gap or make the correction without subsequent detection.

Upon the same command to "record," the percipient recorded his guess first as to the Color of the target card. All percipients had before them a key which displayed samples of the colors and assigned a number to each. The color number was written on the percipient's record sheet to minimize confusion over the name of the color and expedite recording and scoring. Next, the percipient checked off which of the five presented Emotions he was feeling at that moment. After the few seconds allowed for scoring, a 
command was given to draw the next card, and the process was repeated. When the deck was exhausted, it was passed to the neighbor alternatively on either the left or the right, who overhand shuffled the cards and returned the deck for the next run. ${ }^{-}$

After the first five runs, a break was given. Upon resumption, the partners switched roles. After the second five runs and break, both roles and decks were changed. A final change of roles was made after the next four runs, and a last four runs made. During testing, the experimenter videotaped the subjects both above and below the table to minimize opportunities for deliberate cheating.

Scoring.-Percipient sheets were checked against agent deck run records to ascertain matches between Color and Emotion. Pearson product-moment correlation coefficients were calculated for all analyses. Alpha criterion for significance was .01 .

Results

Scores for the two decks were not significantly different on either the color or emotion scores (Color: $t_{122}=.65, p=.52$; Emotion: $t_{123}=-1.11, p=$ .27). No further distinction was made between the two decks.

Charisma scores for agents correlated insignificantly with Color scores from the telepathy test $\left(r_{12}=.12, p>.1\right.$, power $\left.=.10\right)$; however, agents' Charisma scores correlated significantly with Emotion scores from the telepathy test $\left(r_{12}=.58, .05>p>.02\right.$, power $\left.=.70\right)$.

The combined Empathy score for percipients correlated insignificantly with Color scores from the telepathy test $\left(r_{12}=.15, p>.1\right.$, power $\left.=.13\right)$. While Empathy scores correlated better with Emotion scores, the result was still insignificant $\left(r_{12}=.35, p>.1\right.$, power $\left.=.30\right)$.

Each Charisma and Empathy score was converted into a percentage of the total possible score for that measure. The Charisma score of the agent was then added to the Empathy score of the percipient. This combined score did not correlate significantly with Color scores for that pair in the telepathy test $\left(r_{12}=.04, p>.1\right.$, power $\left.<.10\right)$. A significant correlation occurred, however, between this combined score and the Emotion scores from the telepathy test $\left(r_{12}=.58, .05>p>.02\right.$, power $\left.=.70\right)$.

\section{Discussion}

Study 2 yielded no statistically significant relationships among telepathy,

"A conccivable flaw in the project design is that the decks were not adequately randomized between runs. Without minimizing this possibility, I conclude that the demands for adequate deck shuffling are perhaps not as high as some believe (Kosambi \& Rao, 1958). Whereas Epstein $\{1977, \mathrm{p} .162\}$ claimed that to randomize the deck, the amateur shuffle operation [which divides the deck into two parts which are interleaved in clusters of two to four cards] must be repeated at least five times, a more optimistic finding is that a four-step riffle, riffle, riffle, overhand fully randomizes a deck (Raloff, 1992, reporting the work of Aric DiPicro). 
empathy, and charisma scores. These data must then be examined with an eye toward the subsequent issue of whether this failure better warrants an abandonment of the hypotheses or a refinement of the experiment.

First, the known methodological weaknesses of Study 2 minimize expectations that it could have generated definitive results. In addition to the usual limits of self-report measures without external validation and the clear weakness of the paper-and-pencil empathy measures particularly, a specifically parapsychological critique would point out that all subjects were in the same room and that no independent record of targets and guesses were made. Moreover, although this paper is written in terms of telepathy, the pilot design does not allow clear differentiation between telepathy and clairvoyance as the possible mechanism of nonsensory transfer of information (Rhine, 1974; Walther, 1986; cf. Dille, 1990). Any deeper exploration into the questions raised should aim to include these improvements (cf. Druckman \& Swets, 1988, p. 174).

Particular attention should be paid in the future to the construct of empathy. A more valid strategy may be less to contrast differences in empathy among individuals than to identify cultural differences and then to see if this cultural patterning correlates with telepathy test outcomes. At one extreme would be empathy-inducing cultural environments such as the Japanese who have as a communicative ideal the concept of ishin-denshin, which may be translated as "communication of thoughts from one mind to another without using language" (Tsujimura, 1987, p. 117). Practice of this concept is the source of the fabled "inscrutability" and taciturnity of Asians. The Koreans have a similar concept, termed $i$-sim jun-sim (Yum, 1987), and both are rooted in Buddhist philosophy. We would predict that persons from these cultures might score better on telepathy tests than those from cultures which explicitly discourage such nonverbal communication.

Such an empathy-denying people would be the Kaluli of Papua New Guinea, who claim that "one cannot know what another thinks or feels.' ... [There] is a cultural dispreference for talking about or making claims about what another might think, what another might feel, or what another is about to do, especially if there is no external evidence" (Ochs \& Schieffelin, 1984, p. 290).

The Kaluli could profitably be compared with the Ifaluk, a people inhabiting a small island in the Pacific. From their cultural perspective, the "point at which the self stops and the other begins is neither fixed nor conceptualized as an impermeable wall. It is considered natural that one person's thought should influence another's. People are frequently characterized as 'following the thoughts/feelings' of others; in doing so, they take on the attitudes, angers, or plans of the other" (Lutz, 1988, p. 88). Thus, those "who are homesick for another will cause the latter to become ill if they 
continue to focus their thoughts/emotions on the missed person" (p. 100, emphasis added); this is the principle mechanism by which spirits allegedly cause the death of living persons (p. 128). Perhaps most interesting of all, this blurring of boundaries is linguistically reflected by "the use of the firstperson plural," which "is nearly as common as that of the first-person singular in statements about mental events" (pp. 88-89).

These contrasting cultural attitudes toward empathy should make the differences both manifest and fundamental, facilitating any hypotheses which depend on these differences. Thus, the Ifaluk would be predicted to perform better on culturally appropriate telepathy tests than would the Kaluli, or perhaps the Sebei, whom Goldschmidt (1975, p. 157) described as having a "low level of affect" and thereby having a "general lack of empathy."

Second, compounding the methodological weaknesses of Study 2 are the statistical limits. While the small number of subjects might be deemed appropriate for an initial exploratory study, it severely limits the inferential power of any statistical analyses. Power is the "probability of rejecting [the null hypothesis] when the [null hypothesis] is false and the [alternative hypothesis] is true" (Kiess, 1996, p. 186). By convention power is preferred to be about .80 , since "A materially smaller value than .80 would incur too great a risk of a Type II error [while a] materially larger value would result in a demand for $N$ that is likely to exceed the investigator's resources" (Cohen, 1992, p. 156). None of the analyses in Study 2 attain power levels of .80 ; in fact, several analyses have power approximating the low level at which Cohen $(1969$, p. 39) suggested it is "probably not worth the effort involved in performing the experiment." Within these constraints, Study 2 would have required unusually strong effects indeed to have achieved statistical significance.

Despite the failure to achieve statistical significance, Study 2 results were not wholly unpatterned. Both Charisma and Empathy scores correlated better with Emotion than with Color scores. This type of information most successfully "transmitted" during a test for telepathy (Rhine, 1969; Matsev, 1983; Plutchik, 1987; Rao \& Palmer, 1987; but compare Ickes, et al., 1990). While one channel performing in accordance with theoretical expectation may be an experimental artifact, both channels performing thus increase the possibility that something of interest is indeed occurring.

Finally, at least some schools within the philosophy of science would support refining the experiment over rejecting the hypotheses within the present context. Grant that reports of "telepathic" experiences are orphan facts, ostensibly valid but unincorporated into the standard scientific perspective. Charisma and empathy are only somewhat better tied to the traditional outlook, although their presence within it is better tolerated. Linking the three experiences together would be what Lakatos (1970) characterizes 
as a "content-increasing" theory, since it would explain telepathy in terms of charisma and empathy and thereby eliminate an orphan fact from the scientific corpus. The thrust of Lakatos' argument is that contrary to the "naive falsification" of Popper, falsification of a theory is achieved not simply in the face of experimental failure but only when that failure is coupled with "the emergence of a better theory" (1970, p. 119). He terms this requirement "sophisticated falsification."

Because the linkage of telepathy, charisma and empathy is a content-increasing theory, the experimental failure of Study 2 is not determinative as we lack a competing theory with equal or better content-increasing effect. I am familiar with no such competitor. Considering in tandem the methodological, statistical, and philosophical aspects of Study 2, as well as the positive outcomes in Study 1, the prudent conclusion should be to preserve the hypothesis of a telepathy-charisma-empathy triad which merits testing in better designed, tighter, and larger studies.

\section{Conclusion}

Telepathy, empathy, and charisma, all being forms of nonsensory communication, may be genetically related. One possibility is that the experience called "telepathy" is interpretable as extraordinarily impressive events of charisma and empathy. From this perspective, the metaphor of a communication distance suggests that agent and percipient "reach" perceptually toward one another, with charisma and empathy respectively. If the partners "touch" one another across this gap, the result is termed "telepathy." Once a connection is made, emotional states are the information most easily communicated through the established link.

Viewed as a whole, the results of the studies reported here are sufficiently suggestive to warrant the effort and expense required to explore the hypothesis properly with an adequately large subject pool and perhaps even to make the desirable cross-cultural comparisons.

\section{REFERENCES}

Al.tror', G. W. (1968) The historical background of modern social psychology. In G. Lindzey \& E. Aronson (Eds.), Handbook of social psychology. (2nd ed.) Vol. 1. Reading, MA: Addison-Wesley. Pp. 1-80.

ANTHONY, J. S. (1982) Interrelationships among bclief in psychic abilities, psychic experiences, and sensation-seeking. Unpublished Ph.D. dissertation, United States International Univer.

BeRLIN, B., \& KAY, P. (1969) Basic color terms: their universality and evolution. Berkeley, CA: Univer. of California Press.

Birren, F. (1950) Color psychology and color therapy: a factual study of the influence of color on buman life. New York: McGraw-Hill.

Brouguton, R. S. (1991) Parapsychology: the controversial science. New York: Ballantine.

Brugger, P., Landis, I., \& Regard, M. (1990) A 'sheep-goat effect' in repetition avoidance: extra-sensory perception as an effect of subjective probability? British Journal of Psychology, $81,455-468$

CARR, B. J. (1983) An experiment to discriminate between telepathy and clairvoyance using 
Ishihara cards and colour-blind agents. Journal of the Society for Psychical Rescarch, 52, 31.44 .

CoHen, J. (1969) Statistical power analysis for the bebavioral sciences. New York: Academic Press.

Conen, J. (1992) A power primer. Psvchological Bulletin, 112, 155-159.

Cross, D. G., \& Silarpley, C. F. (1982) Measurement of empathy with the Hogan Empathy Scale. Psychological Reports, 50, 62.

D'Andrade, R. (1990) Somc propositions about the relations between culture and human cognition. In J. W. Stigler, R. A. Shweder, \& G. Herdt (Eds.), Cultural psychology: essays on comparative buman development. Cambridge, UK: Cambridge Univer. Press. Pp. 65-129.

D'Andrade, R., \& Egan, M. (1974) The colors of emotion. American Ethnologist, 1, 49-63.

Dillarar, J. P., \& Hunter, J. F. (1989) (On the use and interpretation of the Emotional Empathy Scale, the Self-consciousness Scales, and the Self-monitoring Scale. Communication Rescarch, 16, 104-129.

DiLıey, F. B. (1990) Telepathy and mind-brain dualism. Journal of the Society for Psychical Research, 56(819), 129-137.

Donovan, J. M. (1992) Charisma, empathy, and the experience of telepathy. Journal of Indian Psychology, 10(1/2), 11-26.

Donovan, J. M. (1997) A model relating empathy, charisma, and telepathy. Journal of Scientific Exploration, 11, 455-471.

Druckman, D., \& Swers, J. (Eds.) (1988) Enhancing buman performance. Washington, DC: National Academy Press.

Dymond, R. R. (1949) A scale for the measurement of empathic ability. Journal of Consulting Psychology, 13, 127-133.

Eisenberg, N., \& Lennon, R. (1983) Sex differences in empathy and related capacities. Psychological Bulletin, 94, 100-131.

Frstein, R. A. (1977) The theory of gambling and statistical logic. New York: Academic Press.

Evans, D. (1996) Parapsychology: merits and limits. In M. Stoeber \& H. Meynell (Eds.), Critical reflections on the paranomnal. Albany, NY: State Univer. of New York Press. Pp. 47 86.

Fenton, E., \& Morrissett, C. (1990) Canned art: clip art for the Macintosh. Berkeley, CA: Peachpit Press.

Fonor, N. (1966) Encyclopedia of psychic science. Secancus, NJ: Citadel Press.

Friedman, H. S., Prince, L. M., Riggio, R. F., \& DiMatteo, M. R. (1980) Understanding and assessing nonverbal expressiveness: the Affective Communication Test. Journal of Personality and Social Psychology, 39, 333-351.

Friedman, H. S., Riggio, R. E., \& Casella, D. F. (1988) Nonverbal skills, personal charisma, and initial attraction. Personality and Social Psychology Bulletin, 14, 203-211.

Gardano, A. C. (1986) Cultural influence on emotional response to color: a research study comparing Hispanics and non-Hispanics. American Joumal of Art Therapy, 24, 119-124.

Got.nschmid, W. (1975) Absent eyes and idle hands: socialization for low affect among the Sebei. Ethos, 3, 157-163.

GreLA, J. J. (1945) Effect on ESP scoring of hypnotically induced attitudes. Journal of Parapsychology, 9, 194-202.

Hogan, R. (1969) Development of an empathy scale. Joumal of Consulting and Clinical Psy. chology, 33, 307-316.

Ickes, W., Stinson, L., Bissonnette, V., \& Garcia, S. (1990) Naturalistic social cognition: empathic accuracy in mixed-sex dyads. Journal of Personality and Social Psychology, 59, 730 742 .

IRwiN, H. J. (1989) An introduction to parapsychology. Jefferson, NC: McFarland.

JAMEs, W. (1956) The will to believe and other essays in popular philosopby. New York: Dover.

Kiess, H. O. (1996) Statistical concepts for the behavioral sciences. (2nd ed.) Boston, MA: Allyn $\&$ Bacon.

Kosambi, D. D., \& RaO, U. V. R. (1958) The efficiency of randomization by card shuffling. Journal of the Royal Statistical Society, Series A (General), 121, 223-233.

Krieger, J., \& RezNiKoFf, M. (1992) Cognitive and projective measures of differentiation and their relationship to empathy. Joumal of Research in Personality, 26, 319-339.

I.aKatos, I. (1970) Falsification and the methodology of scientific research programmes, In I Lakatos \& A. Musgrave (Eds.), Criticism and the growth of knowledge. Cambridge, UK Cambridge Univer. Press. Pp. 91-195. 
Levenson, R. W., \& Ruef, A. M. (1992) Empathy: a physiological substrate. Journal of Personality and Social Psychologv, 63, 234-246.

Levy, B. I. (1984) Research into the psychological meaning of color. American Journal of Art Therapy, 23, 58-62.

Lindholm, C. (1990) Charisma. Cambridge, MA: Basil Blackwell.

LovitTs, B. E. (1981) The sheep-goat effect turned upside down. Journal of Parapsychology, 45, $293-309$.

L.uT7, C. A. (1988) Unnatural emotions: everyday sentiments on a Micronesian atoll and their challenges to Western theory. Chicago, IL: Univer. of Chicago Press.

Maltsev, O. (1983) Emotions and psvcho-informational interactions. Psi Rescarch, 2(2), 46-50.

McCienon, J. (1984) Deviant science: the case of parapsychology. Philadelphia, PA: Univer. of Pennsylvania Press.

Mehrabian, A., \& Epstein, N. (1972) A measure of emotional empathy. Journal of Personality, $40,526-543$.

Nanko, M. J. (1986) Critical thinking ability, dogmatism, ambiguity tolerance and belief in the paranormal. Unpublished Ph.D. dissertation, United States International Univer.

Ochs, E., \& SchiffFri.in, B. B. (1984) Language acquisition and socialization: three developmental stories and their implications. In R. A. Shweder \& R. A. LeVine (Eds.), Culture theory: essays on mind, self, and emotion. Cambridge, UK: Cambridge Univer. Press. Pp. $276-320$.

Palmer, J. (1971) Scoring in ESP tests as a function of belief in ESP: Part I. The sheep-goat effect. Joumal of the American Society for Psychical Rescarch, 65, 373-408.

P'uutchiк, R. (1987) Evolutionary bases of empathy. In N. Eisenberg \& J. Strayer (Eds.), Empathy and its devclopment. Cambridge, UK: Cambridge Univer. Press. Pp. 38-46.

RalofF, J. (1992, June 6) In the name of the game. Science News, 141, 380.

RaO, K. R., \& Palmer, J. (1987) The anomaly called psi: recent research and criticism. Behavioral and Brain Scicnces, 10, 539-643.

Rhine, J. B. (1953) New world of the mind. New York: William Sloane.

Rhine, J. B. (1974) Telepathy and other untestable hypotheses. Joumal of Parapsychology, 38 , $137-153$.

Rhinf, L.. E. (1969) Case study review. Journal of Parapsychology, 33, 228-266.

Schmeidler, G. R. (1943) Predicting good and bad scores in a clairvoyance cxperiment: a preliminary report. Joumal of the American Socicty for Psycbical Research, 37, 103-110.

Schmeideer, G. R. (1985) Belief and disbelicf in psi. Parapsychology Revicw, 16(1), 1-4.

Schmeideler, G. R. (1988) Parapsychology and psychology: matches and mismatches. Jefferson, NC: McFarland.

Schmeidier, G. R., \& MCConnell, R. A. (1958) ESP and personality patterns. New Haven, CT: Yale Univer. Press.

StraYer, J. (1987) Affective and cognitive perspectives on empathy. In N. Eisenberg \& J. Strayer (Eds.), Empathy and its development. Cambridge, UK: Cambridge Univer. Press. Pp. 218-244.

ToвacyK, M., \& MiLford, G. (1983) Belief in paranormal phenomena: assessment instrument development and implications for personality functioning. Journal of Persenality and Social Psychology, 44, 1029-1037.

Tsujmura, A. (1987) Some characteristics of the Japanese way of communication. In D. L. Kincaid (Ed.), Communication theory: eastern and western perspectives. San Diego, CA: Academic Press. Pp. 115-126.

VIRTANEN, L. (1990) "That must bave becn ESP!": an examination of psychic experiences. (J. Atkinson \& T. Dubois transl.) Bloomington, IN: Indiana Univer. Press.

WAlther, E. (1986) Telepathy: a testable hypothesis. Journal of the Socicty for Psychical Research, 53, 201-209.

WhITE, R. A. (1994) An experience-centered approach to parapsychology. In R. A. White (Ed.), Exceptional buman experience: background papers. Dix Hills, NY: Exceptional Human Experience Network. Pp. 15-33.

YUm, J-O. (1987) Korean philosophy and communication. In D. L. Kincaid (Ed.), Communication theory: castern and western perspectives. San Diego, CA: Academic Press. Pp. 71-86.

Accepted May 28, 1998. 